\title{
Aviation Dentistry: is it an Unexplored Field of Dentistry? A Cross-Sectional Study
}

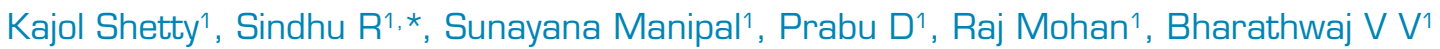

How to cite

R Sindhu (D) https://orcid.org/0000-0002-4914-0376

\begin{abstract}
Shetty K; Sindhu R; Manipal S; Prabu D; Mohan R; Bharathwaj W (2020) Aviation Dentistry: is it an Unexplored Field of Dentistry? A Cross-Sectional Study. J Aerosp Technol Manag,

12: e2420. https://doi.org/10.5028/jatm.v12.1120
\end{abstract}

\begin{abstract}
Background: There is an increase in the number of flight travellers and with it comes the risks of developing in-flight dental conditions that evokes pain at higher altitudes. The knowledge about such conditions are necessary among the dentists to prevent such phenomena. Aim: To assess the knowledge and familiarity about aviation dentistry among dentists. Methodology: A cross-sectional questionnaire-based study conducted among 170 postgraduates and dental professionals in a private dental institution. A pilot study was conducted among 30 individuals, and the questionnaire was validated. Data was analysed by SPSS package 20. Descriptive statistics and chi-square tests were used. Results: $61.8 \%$ of the individuals were not familiar with the term aviation dentistry. A statistically significant association was found between familiarity with aviation dentistry and the qualification of the dentists and also between familiarity with aviation dentistry and years of experience of the dentists with a $p$ value $<0.05$. Conclusion: The study result shows the lack of knowledge about aviation dentistry among postgraduates and dental professionals.
\end{abstract}

KEYWORDS: Aviation; Barotrauma; Dentistry; Flight.

\section{INTRODUCTION}

Aviation dentistry deals with the oral and dental health status of the aviators which primarily deals with the diagnosis, disorders related to the oral and maxillofacial regions and their impact on those who travel to such an environment with abnormal change in atmospheric pressure. The change in atmospheric pressure occurs as the person continues to travel at high altitude (about $18,000 \mathrm{ft}$ and above) (Lakshmi 2014). At the beginning of the twentieth century, after the innovation of modern flights, in-flight pathologic and physiologic conditions related to the oral and maxillofacial region has been reported. It was also reported that dental and other oral problems was found to be the cause of such in-flight phenomena wherein after, the guidelines for dental care of aircrew members has been published for over the last 60 years.

Since the growth in the aviation sector escalates, the number of passengers flying, leisure pilots, flight attendants, airline and military pilots are growing notably, which makes dentists encounter more frequently such patients who require immediate care. Most frequent in-flight complaints reported includes fracture of dental restorations, sharp or diffuse pain, tooth fractures, xerostomia, etc. The most commonly encountered conditions include barodontalgia, barotrauma and odontocrexis (Zadik et al. 2006).

Barodontalgia or aerodontalgia is a condition where dental pain is evoked by changes in barometric pressure which might be severe enough to cause in-flight vertigo (Zadik 2010). The condition is provoked in the presence of any miniature void created

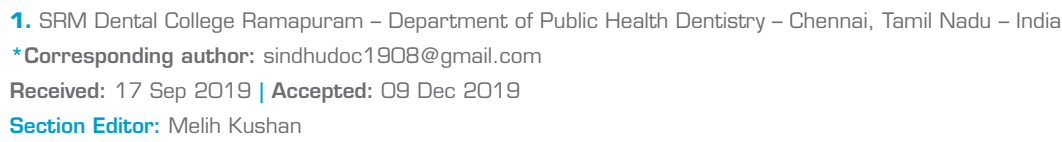


within a filled tooth, defective tooth restorations, pulpitis, dental caries, apical periodontitis, periodontal pockets, impacted tooth and mucous retention cysts (Lurie et al. 2007). During ascent, as the pressure reduces, there is dissolution of gases into the blood vessels; due to which the gas bubbles enter the pulp which triggers the nerve endings to evoke pain (Hutchins and Reynolds 1947). A clinical benefit of barodontalgia reported that it helps the dentists to locate early caries, periodontal abnormalities and leaky restorations. It has also been reported that placement of zinc oxide eugenol base as preventive measure when reversible pulpitis was the underlying cause for barodontalgia (Zadik 2009a).

Barotrauma refers to the physical trauma of body tissues wherein the gas present in the various hard or soft body structures expands or compresses which is caused by rapid changes in the atmospheric pressure. It is of both dental and nondental origin. It is experienced commonly in air travellers, scuba diving, hyperbaric oxygen therapy or exposure to shock waves from an explosion (Mandke and Garg 2015). Nondental origin of barotrauma includes conditions such as head and face barotrauma, barosinusitis, external otic barotrauma, barotitis media and barotrauma-related headache. Dental barotrauma involving in-flight dental fractures and loss of restorations during high altitude flight has been reported since World War II period (Zadik 2009b).

Calder and Ramsay (1983) described the term "odontocrexis" (in Greek, tooth explosion) when they observed tooth fractures in aircrew members at high altitudes with rapid barometric pressure change (Gunepin et al. 2010). The tooth damage was experienced in cases with leaky defective restorations when the trapped void expands at high altitudes and leads to fracture (Zadik et al. 2006). Another common complaint reported by long range fighter pilot was xerostomia, induced due to decrease in oxygen at high altitudes causing prolonged dryness. This could result in increased incidence of dental caries and disturbance of the mucous membrane of mouth and nasopharynx (Anuradha and Grover 2010).

All of these conditions can be avoided only if the patients are instructed about the complications and restrictions in flying after dental treatment by the dentists, for which it is imperative for the dentists to be aware of such conditions. Thus, this study aims to assess the knowledge about aviation dentistry among the dentists.

\section{METHODOLOGY}

A descriptive, cross-sectional study using a questionnaire was conducted among 170 dental professionals over a period of 3 months from September to November 2017. The study was independently reviewed and ethical approval for the study was obtained from the Institutional Review Board of SRM Dental College and Hospital, Chennai, India. The study was carried out according to the guidelines of the World Medical Association Declaration of Helsinki.

The samples for this study were taken from a private dental institution and it included postgraduates and dental professionals. A pilot study was conducted among a sample of 30 participants which includes postgraduates and dental professionals. These samples were not included in the final samples. Based on the pilot study, a sample size of 170 was derived and cluster sampling technique was used to select the required samples for the study. The study samples included 102 postgraduates and 68 dental professionals of a private dental institution.

A self-administered questionnaire was prepared in English and consisted of a set of 15 questions with mostly objective type that included sociodemographic factors, qualification and years of experience of the dentists, their knowledge on the familiarity of the conditions and their experience encountered with such conditions. The questionnaire was pretested for validity and reliability among the 30 individuals included in the pilot study, which were not included in the final analysis. The Cronbach's alpha test showed a reliability coefficient of 0.85 , which was found to be satisfactory for conducting the study.

The consent procedure was approved by the Institutional Review Board and verbal consent was obtained from all the study participants. The questionnaire was distributed to the study participants and sufficient time was given to them to fill the questionnaire, which were collected back on the same day.

SPSS Base 20.0 statistical package was used for data analysis. Descriptive statistics were used to determine the distribution of the participants and their knowledge on aviation dentistry. Chi-square test was used to assess the association between qualification and years of experience with their familiarity about aviation dentistry and the level of significance was set at $p$ value $\leq 0.05$. 


\section{RESULTS}

A total of 170 individuals responded to the questionnaire. There were no missing responses and the response rate was $100 \%$. The distribution of the study participants includes 80 (47.1\%) males and 90 (52.9\%) females. Of the whole study population, maximum number of respondents belonged to the age group of $23-28$ years $(46,27.05 \%)$. The sample constituted a greater number of qualified undergraduates (65.3\%) compared to postgraduates (34.7\%) (Table 1). 1.8\% of the individuals were "quite familiar" with the term aviation dentistry, $36.5 \%$ had reported that they have "heard about it" and the majority of the individuals (61.8\%) had reported it was "new to me" (Fig. 1).

Table 1. Distribution of study participants according to age, gender, qualification and year of experience $(n=170)$

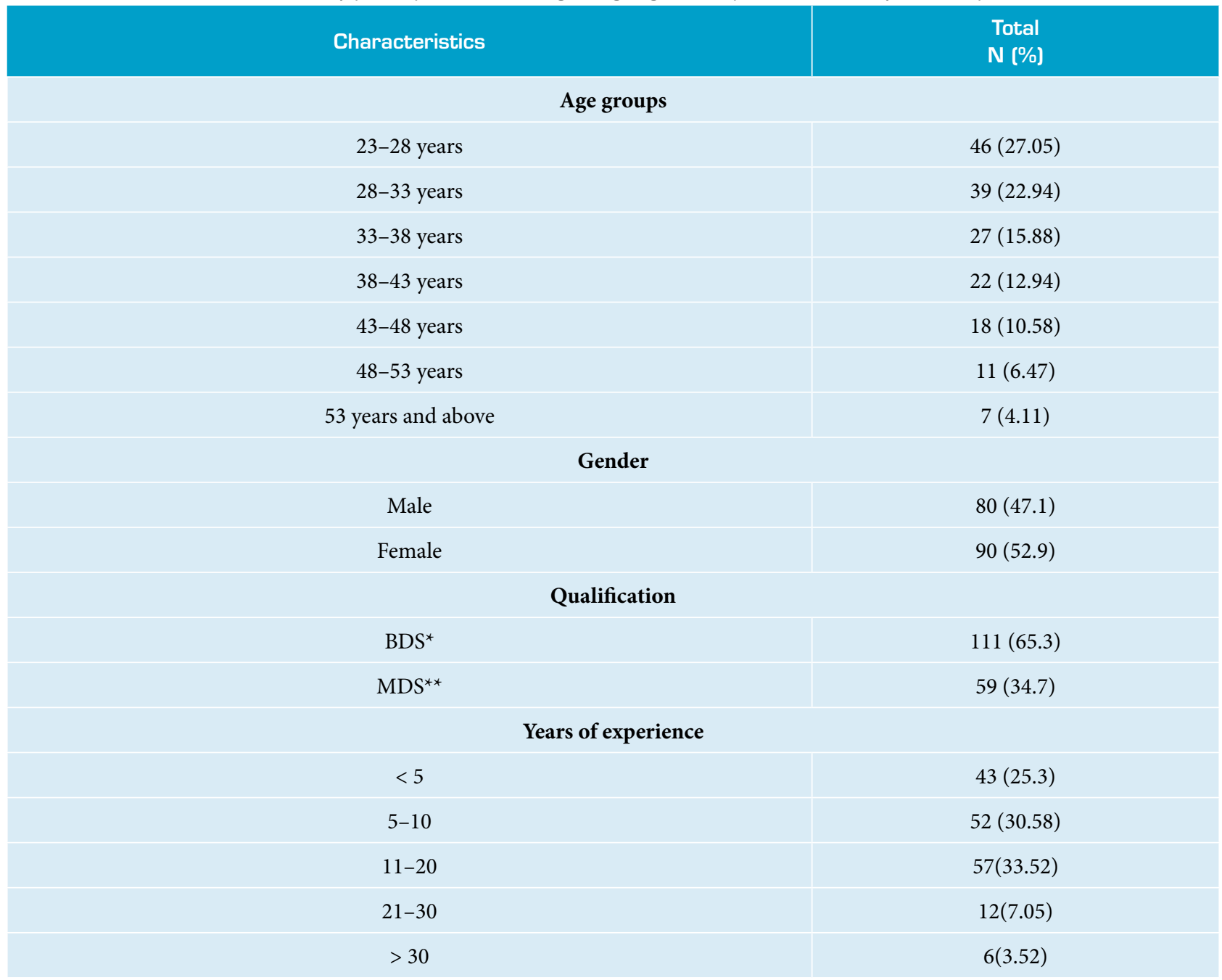

*BDS: Bachelor of dental surgery; **MDS: Master of dental surgery.

The least knowledge was reported with odontocrexis (12.9\%) compared to barodontalgia (62.9\%) and barotrauma (44.7\%). The majority of the individuals reported the causes for barodontalgia, barotrauma and odontocrexis to be pulpitis (45.3\%), none (41.8\%) and none (64.7\%) respectively. $97.6 \%$ of the individuals were aware of the special dental care required for pilots and aircrew members, $2.4 \%$ of the dentists have reported dealing with pilots/aircrew patients, $68.8 \%$ think frequent flyers are at risk and $85.3 \%$ of them reported that preventive measures should be taken by the dentists (Table 2). The majority of the dentists perceived pulpitis $(22.9 \%)$ as the major condition that requires flight restriction, followed by fractured tooth (14.7\%) (Fig. 2). 


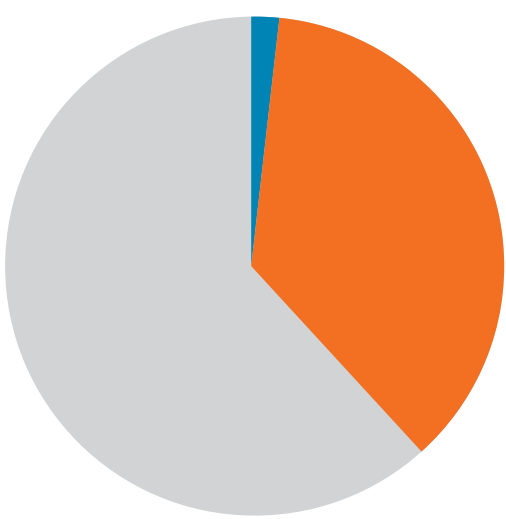

Quite Familiar

Heard about it

New to me

Figure 1. Awareness about aviation dentistry among the study participants

Table 2. Familiarity with the terms and responses to the questions by the study participants

Response

Yes

No

\section{Cause of barodontalgia}

Pulpitis

Extraction

Xerostomia

All of above

None

Barotrauma

Yes

No

Sinusitis

Pulpitis

Extraction

All of above

None

Odontocrexis

Yes

No

Cause of barotrauma

\begin{tabular}{|c|c|}
\hline $\begin{array}{c}\text { Yes } \\
\text { No }\end{array}$ & $22(12.9)$ \\
\hline \multicolumn{1}{|c|}{ Cause of odontocrexis } \\
\hline Fracture/leaky restorations & $148(87.1)$ \\
\hline Haemorrhage & $29(17.1)$ \\
\hline Extraction & $2(1.2)$ \\
\hline All of above & $9(5.3)$ \\
\hline None & $20(11.8)$ \\
\hline Pilots/aircrew members need special dental care & $110(64.7)$ \\
\hline Dealt with pilots/aircrew patients & $166(97.6)$ \\
\hline Frequent flyers are at risk & $4(2.4)$ \\
\hline Preventive measures need to be taken by dentists & $117(68.8)$ \\
\hline
\end{tabular}

Frequency [\%]

107 (62.9)

63 (37.1)

77 (45.3)

18 (10.6)

18 (10.6)

12 (17.1)

45 (26.5)

76 (44.7)

94 (55.3)

33 (19.4)

29 (17.1)

19 (11.2)

18 (10.6)

$71(41.8)$

22 (12.9)

48 (87.1)

9 (17.1)

$2(1.2)$

(64.7)

(97.6)

17 (68.8)

145 (85.3) 


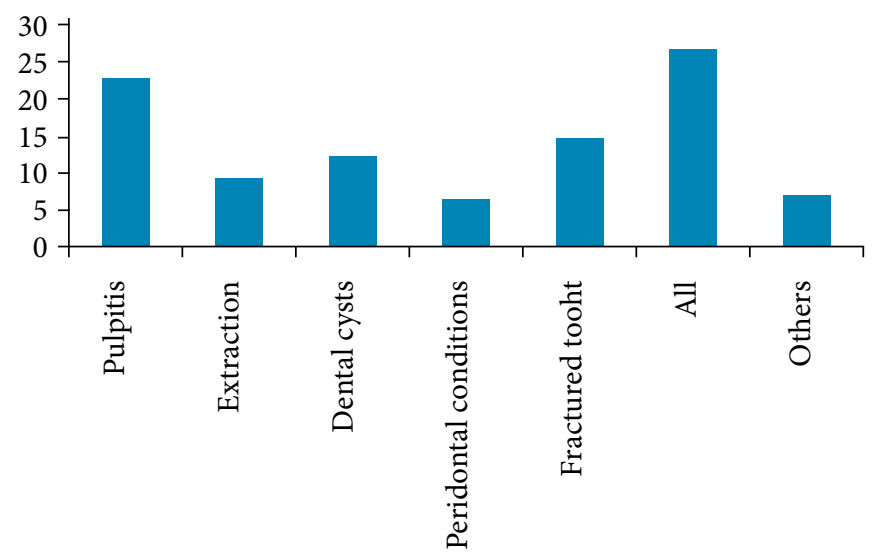

Figure 2. Conditions that need flight restrictions.

Statistically, significant results were obtained on analysing the relationship between familiarity with aviation dentistry and qualification of the dentists with Pearson's chi-square value 146.085 and $\mathrm{p}$ value $<0.05$. The MDS graduates were found to be more familiar with the knowledge about aviation dentistry compared to BDS graduates. Also, significant results were obtained between familiarity with aviation dentistry and the dentists' experience, with Pearson's chi-square value 381.707 and $\mathrm{p}$ value $<0.05$. The dentists with more experience were found to be more familiar with the knowledge about aviation dentistry compared with the dentists with less experience (Table 3). There was no statistically significant association found between the qualification or years of experience and the number of dentists who dealt with the pilots/aircrew members.

Table 3. Association between qualification and years of experience of the dental professionals with the familiarity of terms

\begin{tabular}{|c|c|c|c|}
\hline Dependent actors & Value & df & Asymptomatic significance (two-sided) \\
\hline Qualification & 146.085 & 2 & $0.05^{*}$ \\
\hline Years of experience & 381.707 & 12 & $0.05^{\star}$ \\
\hline
\end{tabular}

*Statistically significant.

\section{DISCUSSION}

Aviation dentistry is an emerging science, which has been much neglected by the dentists and lacks awareness about the significance. Though there are numerous literature available about aviation dentistry, the awareness about it among the dentists was not assessed. The aim of this study was to assess the knowledge about aviation dentistry among dentists. In the present study, only $1.8 \%$ of the individuals were familiar with the terms in aviation dentistry and $61.8 \%$ were totally unfamiliar about them.

The present study which was conducted in $21^{\text {st }}$ century, only $62.9 \%$ of the individuals were familiar with the term barodontalgia and only $45.3 \%$ of the individuals knew pulpitis was the cause for it. A study reported by Calder and Ramsey (1983) where the incidence of barodontalgia during World War II which happened in $20^{\text {th }}$ century was up to 1 to $8 \%$ among the military flight attendants and 9.5\% of American aircrews reported at least one episode of barodontalgia (Calder and Ramsey 1983). This shows the lack of acquaintance by the dentists regarding aviation dentistry for several decades.

An in vitro study reported by Calder and Ramsey (1983) found that the teeth with leaky restorations when subjected to exaggerated pressure produced a synergistic effect and reduced the size of venules leading to cessation of circulation that eventually leads to pulpal death (Calder and Ramsey 1983). In the present study the least knowledge was found to be about the term odontocrexis, of which only $12.9 \%$ were familiar with and the cause being fracture/leaky restorations was reported to be known only by $17.1 \%$. Similar to barodontalgia, paucity of literature could be the reason for such a lack of knowledge about the term "odontocrexis" among dentists. 
The responses to the causes of barotrauma and odontocrexis reported by the individuals were not appropriate as the original causes for those conditions were not chosen by the individuals, which shows the predicament of the dentists with respect to their knowledge about aviation dentistry. In the present study, the conditions reported by the dentists that needs flight restrictions are in accordance with the study reported by Zadik et al. (2007) after analysing in-flight barodontalgia among 29 cases in military aircrew, the most common in-flight pain causes reported were recently restored teeth (29.6\%), barosinusitis (18.5\%), and pulp necrosis/peri-apical periodontitis (18.5\%) (Zadik et al. 2007).

The MDS graduates were found to be more familiar with knowledge regarding aviation dentistry. This is justified as the increased years of experience among dentists was found to be associated with the knowledge they possess regarding aviation dentistry. The reason for the neglect and lack of awareness could be due to lack of knowledge regarding the conditions; inadequate research literatures and the unavailability of these contents in the dental curriculum regarding aviation dentistry.

There are few limitations in this study; it was conducted using a questionnaire that was self-reported by the dentists, which could have led to information bias; the assessment of awareness about the conditions and the experience among aircrew members could not be carried out due to time deficit and it will be carried out as a second phase of this research in future.

The recommendations include creating evidence-based guidelines for dental care of aircrew members in the dental curriculum which would help the dentists gain knowledge about the prevention of such conditions; future studies in the field of aviation dentistry could be carried out; and a compulsory routine dental examination should be done for the aircrew members and frequent flyers before their departure.

\section{CONCLUSION}

Dental care is an integral part of aircrew's operative fitness which could be jeopardized by the reduction in air density and air pressure at higher altitudes and therefore it is mandatory to be taken care of. Flight surgeons and dentists needs to be aware of flight-related dental phenomena. Although dental breakage seems rare in the aviation environment, it may be prevented by having routine dental examinations and giving adequate attention to existing dental restorations. The flying population would be served better by understanding those conditions and increasing awareness of the limitations of current knowledge about such conditions.

\section{AUTHOR'S CONTRIBUTION}

Conceptualization, Shetty K and Sindhu R; Methodology, Shetty K, Sindhu R and Manipal S; Investigation, Shetty K and Sindhu R; Writing - Original Draft, Shetty K and Sindhu R; Writing - Review and Editing, Manipal S and Bharathwaj VV; Resources, Shetty K.; Supervision, Prabu D and Mohan R.

\section{ACKNOWLEDGMENTS}

Editors and authors are thankful to Fundação Conrado Wessel for providing the financial support for publishing this article.

\section{REFERENCES}

Anuradha P, Grover S (2010) Aviation Dentistry: "the neglected field by dentists in India". A Review Article. J Indian Assoc Public Health Dent. 8(16):36-39. 
Calder IM, Ramsey JD (1983) Ondontecrexis - the effects of rapid decompression on restored teeth. J Dent. 11(4):318-323. https:// doi.org/10.1016/0300-5712(83)90116-1

Gunepin M, Derache F, Audoual T (2010) Fracture of a sound tooth in a pilot under hypobaric conditions. Aviat Space Environ Med. 81(7):691-693. https://doi.org/10.3357/ASEM.2754.2010

Hutchins HC, Reynolds OE (1947) Experimental investigation of the referred pain of aerodontalgia. J Dent Res. 26(1):3-8. https://doi.or g/10.1177/00220345470260010401)

Lakshmi B, Sakthi DS (2014) Aviation dentistry. J Clin Diagn Res. 8(3):288-290. https://doi.org/10.7860/JCDR/2014/7232.4189

Lurie O, Zadik Y, Einy S, Tarrasch R, Raviv G, Goldstein L (2007) Bruxism in military pilots and non-pilots: tooth wear and psychological stress. Aviat Space Environ Med. 78(2):137-9.

Mandke L, Garg S (2015) Aviation dentistry: new horizon, new challenge. Int J Contemp Dent Med Rev. 3(350115): 1-4.

Zadik Y, Einy S. Aviation dentistry. In: Goldstein L, editor. Aviation Medicine. Tel-Aviv: The Publishing House of Israeli Ministry of Defense; 2006. p. 197-208.

Zadik Y, Einy S, Pokroy R, Bar Dayan Y, Goldstein L (2006) Dental fractures on acute exposure to high altitude. Aviat Space Environ Med. 77(6):654-657.

Zadik Y, Chapnik L, Goldstein L (2007) In-flight barodontalgia: analysis of 29 cases in military aircrew. Aviat Space Environ Med. 78(6):593-596.

Zadik Y (2009a) Aviation dentistry: current concepts and practice. Br. Dent. J. 206(1):11-16. https://doi.org/10.1038/ sj.bdj.2008.1121

Zadik Y (2009b) Barodontalgia. J Endod. 35(4):481-485. https://doi.org/10.1016/j.joen.2008.12.004

Zadik Y (2010) Barodontalgia: what have we learned in the past decade. Oral Surg Oral Med Oral Pathol Oral Radiol. 109(4):65-69. https://doi.org/10.1016/j.tripleo.2009.12.001 